\title{
Towards a Sustainable Services Innovation in the Construction Sector
}

\author{
Sylvain Kubicki ${ }^{1}$, Eric Dubois ${ }^{1}$, Gilles Halin ${ }^{2}$, and Annie Guerriero ${ }^{1,2}$ \\ ${ }^{1}$ Public Research Centre Henri Tudor \\ 29, av. J.F. Kennedy, L-1855 Luxembourg-Kirchberg, Luxembourg \\ \{sylvain.kubicki, eric.dubois, annie.guerriero\} atudor.lu \\ ${ }^{2}$ Research Centre in Architecture and Engineering \\ 2, rue Bastien Lepage, 54001 Nancy, France \\ gilles.halinecrai.archi.fr
}

\begin{abstract}
In this paper, we report on a business case in the construction sector where we have designed and prototyped an innovative Web-based distributed document management application. It supports various exchange and sharing of information services between the different stakeholders involved in a construction project. The development of the application is based on a serviceoriented architecture and follows a systematic model-driven engineering approach. Besides the application itself, the paper also reports on a Sustainable Services Innovation Process (S2IP) guiding our activities related to the valorization and the successful technology transfer of a demonstrator into an innovative product. We illustrate how this innovation process has been applied to this business case in the construction sector where a networked value constellation has been identified and realized with professionals of the construction sector (including a standardization body), software houses and our technology transfer centre.
\end{abstract}

Keywords: service oriented architecture, model-driven engineering, science for service systems, open and networked innovation process, networked value constellation, construction domain.

\section{Introduction}

Cooperation between actors is essential for the success of a construction project. The short-lived groups of actors, the heterogeneity of stakeholders and of the local strategies of their firms are the main specificities of AEC (Architecture, Engineering and Construction) sector activities. Indeed, the diversity of projects and architectural realizations is added to the complexity of groups of stakeholders and relations among them. In this context, the improvement and the change of work methods takes time, and there are clear opportunities for innovation through IT services.

In Luxembourg, to answer to this need, the Public Research Centre Henri Tudor (CRPHT) has been engaged in several R\&D projects, most of them in a PPP (Public/Private Partnership) approach with different stakeholders active in the sector 
as well as with the CRTI- ${ }^{1}$, the national professional association promoting new usages of ICT in the construction sector and its associated standards. These projects have resulted in several demonstrators and prototypes $[1,2]$, the latest one, dealing with a document management services system supporting construction projects, is the focus of this paper. Developing demonstrators is clearly an important activity in a global innovation process in order to get the support of early adopters through experiments and validation. However such demonstrators are only one of the elements that is part of a complete innovation chain resulting in a successful technology transfer. From its past experiences, CRPHT has built and continuously improved the elements of this chain, resulting in a so-called S2IP (Sustainable Service Innovation Process). S2IP supports a networked and open innovation approach [3] based on the identification of a networked value constellation [4] making sustainable this innovation. In this paper we illustrate how the S2IP has been applied to the demonstrator developed for the innovative document management services system.

The structure of the paper reflects the twofold orientation of this work, namely the development of the innovative document management services system demonstrator as well as of the technology transfer innovation process associated with this demonstrator itself. The approach for designing new document management services is presented in Section 4 where is detailed the followed model-driven service design and architectural approach used for building a demonstrator (prototype). The work is mainly based on the instantiation of a meta-model that has been built for understanding the nature of cooperation and collaboration activities taking place in the construction sector. The metamodel is presented in Section 2. Transforming an innovative demonstrator into a sustainable innovation is the target of the S2IP whose generic associated activities are introduced in Section 3. Its application based on the identification of a networked value constellation making sustainable the original demonstrator is detailed in Section 5. Section 6 concludes with a summary of the paper and with an overview of our future plans.

\section{Electronic Cooperation in the Construction Sector}

In this section, we first start by motivating the need for research in new electronic platform for supporting cooperation and collaboration dedicated to the specific services and associated constraints of the AEC sector. Then we report on actual research results regarding the definition of a meta-model associated with the nature of the cooperation in the sector and explain the methodological approach followed in the development of the demonstrator.

\subsection{Cooperative Practices in AEC}

The AEC business market is largely driven by building \& infrastructure projects demand. Such projects involve temporarily teams of heterogeneous actors (architects,

1 The Resource Centre for Technologies and Innovation in Construction (CRTI-B) is a standardization body involving all the representative building trades in Luxembourg (owners, architects/engineers and contractors) in more than 40 thematic working groups. It was created in 1990. http://www.crtib.lu 
engineers, contractors, material providers, etc.) able to respond to the customer's requirements (namely its architectural program). Each of these heterogeneous firms has its own internal processes, methods and IT infrastructures. Then, the project's activity today is characterized by a low-level of integrated design \& construction collective processes.

In this particular context, the "concurrent engineering methods and tools" applied for many years in several other industries (e.g. automotive, aerospace) are not well adapted to the specificities of cooperation in AEC projects. Thus, our research is considering an alternative concept of "cooperative engineering" [5] favoring mutual adjustment, trust between practitioners and enabling the necessary flexibility of processes realization and the need for an adapted IT environment.

We underline that collective processes have not to be described in the details in order to be flexible. Then we think that numerous process modeling approaches (both methods and IT support) are not well adapted to our case. But "working processes" could be described and agreed at a "high level", on the basis of a common and shared vocabulary (more details in Section 2.2) between actors of the domain. That is what the CRTI-B working groups did (more details in Section 3.2), with the consensus of all the involved representative partners. Then, IT support can be considered from the perspective of these cooperative (best) practices.

\subsection{A Methodological Approach of Cooperation Support}

In the role of technology transfer centre, CRPHT is not developing real software products but more demonstrators (or prototypes) that can be used for the purpose of experiments. The goal is to demonstrate the benefits of the new features to the different stakeholders of the sector. In the targeted AEC sector, for developing rapidly and in a flexible way these demonstrators, we are following a Model Driven Engineering (MDE) approach.

This approach is based on model development, steering both domain analysis and tool engineering. It is largely based on Model Driven Architecture (MDA) for software systems development [6] where the objective is to define a framework of certified industrial standards (MOF, UML). In parallel, the Model Driven Engineering (MDE) research area is an evolution aiming to unify different technical spaces (XML, ontology etc.). It does not focus on a unique technology: it is an integrative approach [7]. MDE recommends the use of meta-models to define domain languages. Models represent real systems. Each model has to be conformed to its meta-model [8, 9]. Finally the transformation concept is a central one, a transformation being itself described with a model.

We use this methodological framework and propose two levels of modeling for the cooperative activity in the AEC domain $[10,11]$. First, a Cooperation Context MetaModel (CCMM) allows us to describe the cooperative activity at a high level of abstraction. This meta-model is used to construct a specific model representing the particular context of a real construction project. The instantiation MOF architecture (M2 > M1 > M0), which we base this reasoning on, nicely fits with in the approach based on models and meta-models from MDE.

Our CCMM (M2) takes into account the existing relations between the different elements of a project (See Figure 1). We identify three main categories of elements 


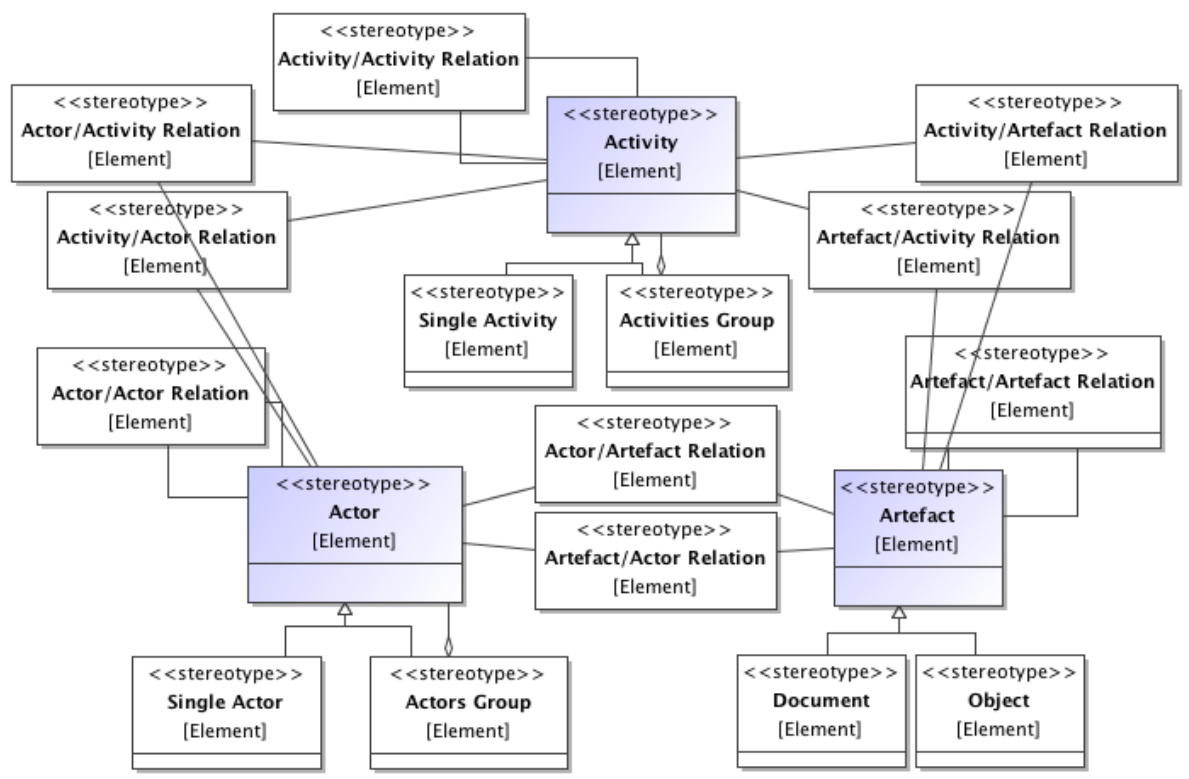

Fig. 1. Cooperation Context MetaModel CCMM - M2 (extract)

existing in every cooperation project: the activity, the actor and the artefact (associated with documents and objects related to an activity). CCMM strengthens the relationships existing between these elements of cooperation.

More details about the CCMM can be found in articles where we have M1 models that have been instantiated to represent specific architectural design context [12] and building construction activity dedicated context [11]. Finally, these Cooperation Context Models (CCM, M1) also enable the description of particular project contexts (M0) representing the business knowledge in which actors cooperate. Note also that an additional benefit of having several M1 models instantiated from the same M2 is to guarantee a better interoperability between different information systems possibly located in different organizations (e.g. engineering offices, architectural agencies...).

In this paper, we will report on a specific new M1 model - focusing on the specific early building design/construction activities and the need for extensively exchanging documents (plans, 3D views, etc.).

\section{Towards a Sustainable Service Innovation Process (S2IP)}

\subsection{An Introduction to the S2IP}

In the previous section, we have introduced the technological and scientific ingredients that are at the basis of the demonstrator offering new services related to AEC document management. Those services and their underlying architecture will be further detailed in Section 4. At this point, we would like to present how the design and the validation of these services are part of a general process applied by CRPHT in a rigorous management of its innovation activities. 
CRPHT is the Luxembourg R\&D centre dedicated to the support of technology transfer and innovation in different technological domains including ICT, health, environment and materials. In the ICT domain, most of these applications are services oriented. This is in line with the nature of the national economy where the service sector accounts for above 85\% percent of total value added in 2006 granting Luxembourg with the first place in the European landscape. According to the EARTO terminology (www.earto.org), CRPHT is a RTO, a public Research and Technology Organization whose is a "specialized knowledge organization dedicated to the development and transfer of science and technology to the benefit of the economy and society". The main mission of a RTO is therefore to provide research, development and innovation services both to private and public beneficiaries according to an open approach (or Public-Private-Partnership) where it acts as interface between universities and firms [13].

In order to perform its public mission, transfer of technologies but also of knowledge, ideas and concepts, CRPHT has defined and applied an innovation management process targeting the support to innovation in services within open partnerships with the targeted beneficiaries [3]. This process is called "Sustainable Service Innovation Process" (S2IP) [14]. It is based on a participatory and collaborative innovation approach in order to sustain deep involvement of the network's actors in the development of innovation services. Targeted services are mostly based on ICT services but packaged into business services, i.e. also including the organizational (processes) and the human (skills and competencies) perspectives. This view is in line with the new research domain of Service Science [15]. The overall structure of S2IP is depicted in Figure 2.

Although the figure may suggest that the S2IP is lifecycle oriented, the reality is that each box corresponds to a process that has to be performed and may be pursued in parallel with other processes in a non strict sequence.

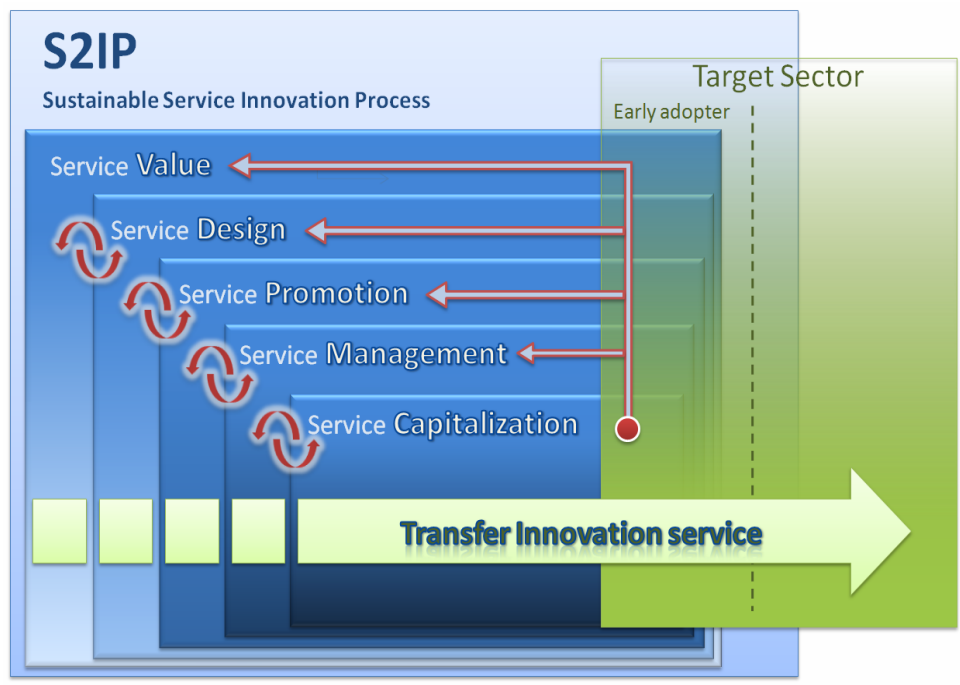

Fig. 2. The S2IP Innovation Process 
The main processes are:

1. Service value and business strategy: This process covers the activities associated with the identification of an opportunity for a new service innovation. They cover a study of the technological feasibility of the service (which, in most cases, requires the building of a demonstrator for the purpose of experiments with early-adopters) as well as a preliminary identification of the business model associated with the value proposition (both expressed in terms of tangible financial elements and of intangible assets).

2. Service design and engineering: This process is associated with the definition of the service not only in terms of its business functional objectives but also in terms of all its required (non-functional) qualities. Thus requires to elicit the strategic goals of the different early-adopters stakeholders involved in the final acceptance of the service as well as to understand the constraints associated with the environment (like specific regulations associated with a sector). From this initial elicitation, requirements have to be formally expressed in terms of properties of the services that can be organized in terms of a service contract (or a service level agreement).

3. Service promotion: Once the service contract has been validated by early adopters, it is important to promote the service to other potentially interested parties. This can be done within an organization through some marketing regarding the socioeconomical sustainability of the service. In a network of organizations or for a sector, this promotion can also include initiatives regarding the branding of the new service through some label definition and associated certification scheme. Ultimately standardization activities run for example at the national or international levels (like e.g. ISO) definitively help in a successful promotion of the service.

4. Service management: This is out of the scope of CRPHT's mission to deploy by itself the service with an organization or within a sector. This is where the market should play its role. However we define and provide tools that can be used by those that will deploy the service for checking and measuring the correctness of its implementation. In particular for each new service we propose metrics associated with the measurement of the quality of the services implementation with respect to the services contract.

5. Service capitalization: Once a services system is deployed within organizations, we can start to collect the feedbacks associated with the measures as well as from assessment performed with the end-users. The analysis of this feedback indicates the possible evolution of the service in terms of new requirements, new business model, etc. Thus this is where new iterations associated with the different processes described above are starting.

\subsection{Applying the S2IP Value Proposition Process to the Building Construction Sector}

Starting from the generic presentation of the S2IP introduced above, we now illustrate its application to our business case in the construction sector by first considering the initial Service Value process and then detailing the four other processes in Section 5 . 
The Service Value process has the twofold objective of "inventing" new services together the strategic business model underlying their acceptance and sustainability. The invention itself is difficult to formally describe but always results from the matching between the knowledge about an innovation opportunity in a sector or a firm, and the knowledge acquired about the potentialities of new technologies, new processes, new methods, etc. In our case, knowledge about the sector was gained through our long-term relationship with the CRTI-B (the national professional association promoting new usages of ICT in the construction sector) in Luxembourg, while knowledge about technology and scientific advances was acquired through our cooperation with the co-author of this paper (namely the MAP-CRAI laboratory in Nancy).

At the centre of our innovation idea was the decision to address the issue of document management through two viewpoints: the human one (i.e. human practices related to document management) and the technological one (i.e. existing software solutions).

The issue of document management in weakly integrated activities needs to focus on the structuring of metadata related to these documents $[16,17]$ rather than on cross-organizational workflows approaches. Metadata management should be considered both the human viewpoint (Why do I share a document? How to document the flow of documents?) and the technological one (How to represent metadata? How should the users fill in metadata?). Regarding such approach, it should be noted that Turk \& Björk suggested one of the first model describing document-related concepts in AEC: presentation, document lifecycle, organization and especially the link with building product models [18].

In this context, designing new document management services for the AEC sector is not really challenging but designing those which really answer to the demand of the CRTI-B is really the topic of the innovation. To do so the following activities were performed with the overall objective of demonstrating the existence of a business model (further detailed in Section 5) for new software services fitting a clearly identified market.

1. During the first activity, enquiries were performed and showed that most of the users were not really satisfied with the existing solutions. Some reasons were collected through brainstorming with practitioners. Interesting synthesis papers also introduced some metrics and indicators to understand the factors of success or failure of AEC groupware solutions [19, 20]. The complexity of their common functionalities and associated services is one important reason [21]. Their low adequacy to the AEC projects specificities (in particular organizational, processes and actors' skills ones) is another reason of the failures in introducing such new IT information systems. Finally technical reasons also have been underlined. Actors have to use numerous IT solutions (one project - one tool) because it is often that the owner or main contractor decides and forces to use such a system in its project.

2. Then, as the decision was taken regarding the development of a new solution, initial needs have been formulated by the end-users themselves through a second enquiry/interview stage. Working practices have been collected by CRPHT who transformed them into a comprehensible set of best working practices. A dedicated working group allowed the practitioners to agree on it in a consensus way. 
3. During the third activity, six releases of the demonstrator have been incrementally developed and regularly validated with 6 working groups (more details in the next Section). These working groups were constituted of 15 AEC practitioners representing several fields (i.e. architects/engineers, owners). The CRPHT team frequently presented the developments' progress. This enabled a validation of the progress but also an early appropriation of the application by its future users.

4. Experiments begun early with only some basic services in order to rapidly debug the system and to let the users better formulate their needs.

\section{A Model-Driven Service Design Approach to a Document Management IT Service in AEC}

The incremental development of the successive releases of the demonstrator took direct benefits of the MDE approach introduced in Section 2 and of its tailoring to the cooperation issues in AEC. The flexibility and the efficiency of this approach for a systematic derivation and evolution of new specific cooperation platforms was already proved by our previous experiences regarding the development of opensource applications, and of their related business services [2].

\subsection{Document Management Business Services}

In our new application, as explained in the previous section, the objective is to support cooperative practices related to the exchange of documents which fits the specificities of the building construction working practices. From interviews and working group meetings with practitioners involved in construction projects (architects, engineers, owners, contractors), we collected information about their practices. After structuring it, and agreeing on it with the involved practitioners, we organized it around seven high level practices. Two examples are:

- Practice 2: A standard naming of project documents is setup and agreed by all the actors involved. It is developed on the basis of the actual norm used in public buildings projects.

- Practice 4: When a document is shared, it is necessary to inform the interested participants of its availability and of all its related modifications.

From the identified cooperation practices $(\mathrm{Px})$ related to document exchange between practitioners, the following services have been incrementally developed:

- A file name management service enables the use of a standard for naming the plans, contracts or meeting reports. It is defined for each construction project and enables to obtain the metadata of a document when it is uploaded. It also ensures the classification of documents in the standard structuring of the project. Standard name is composed of fields and separators. A web service parses the name of the document submitted by the user and interprets its content. If the user uses standard names for his documents, he has just to check if the name is correct. If he does not, he can rename his file using the field contents that the tool suggests him.

- A notification service allows the users to receive notification when a document is uploaded, updated or when various actions are performed (such as leaving a 
reaction, assigning a request and so on). For example an engineer designing its plan on the basis of the architect's one is automatically informed of the upload of a new architect's index, which could be of interest for him.

- A request management service has been developed to manage and keep trace of the interactions between the users. The author of a document can inform someone else that a document has been uploaded. He can also make a request for validation or ask for a reaction. Requests, "due date" and "accomplished date" are then stored and enable to trace the state of a document (validated, waiting for a validation, rejected).

- The reaction service traces the discussions between users about a document and allows them for example to directly inform the owner of a change.

- Finally, a privacy management service enables to manage privacy areas in which the users are authorized to access or not: a first area is restricted to the designers (architects, engineers), a second one allows the owner to see the plans he has to validate, and a third one is completely public and accessible for all the contractors.

\subsection{Development of the Demonstrator}

Today most of the solutions are based on a classical client/server architecture enabling the description, storage and retrieval of cooperation context data in a database. In our case, for the purpose of openness and ease of integration with existing tools, we choose to orient our developments towards a service-based architecture. Examples of such architectures in AEC include the solution developed in the ISTforCE EU project [22] and the one implemented in the e-Nvision project [23].

Our services' platform manages the cooperation context, based on a specific construction business-domain model instantiated from the cooperation context metamodel CCMM) presented in section 2.2. Following the Model-Driven Engineering approach summarized in the right part of Figure 3, we have built a specific cooperation context (M1) associated with the work practices described in the previous sub-section and derived from CCMM. This modeling framework enables to define an adaptable and flexible business context which was useful in the incremental development of the different demonstrator's releases. On our case, M1 represents the specific context of specific early building/construction activities characterized by many exchanges of documents (plans, 3D views, texts) between different actors (firms, agencies, control bodies, etc.). For example, in the M1, we can manage explicitly the relationships existing between the author of a document (e.g. a plan) and the other actors who have to validate it.

The implementation of the business domain context through the use of IT services requires to use the same modeling framework to guarantee the alignment between the concepts introduced at each modeling level. The IT Service metamodel (left part of Figure 3) describes existing visualization modes, designed business processes, usable functional resources and the configuration elements. The metaconcept matching at M2 level enables to define IT services adapted to specific business cooperation contexts by using business concepts when configuring the IT service (M1 level).

The business-oriented services described above have been developed through the use of Web services. The aim is to facilitate their integration in existing software infrastructures used by some of our partners. These Web services are described in the 


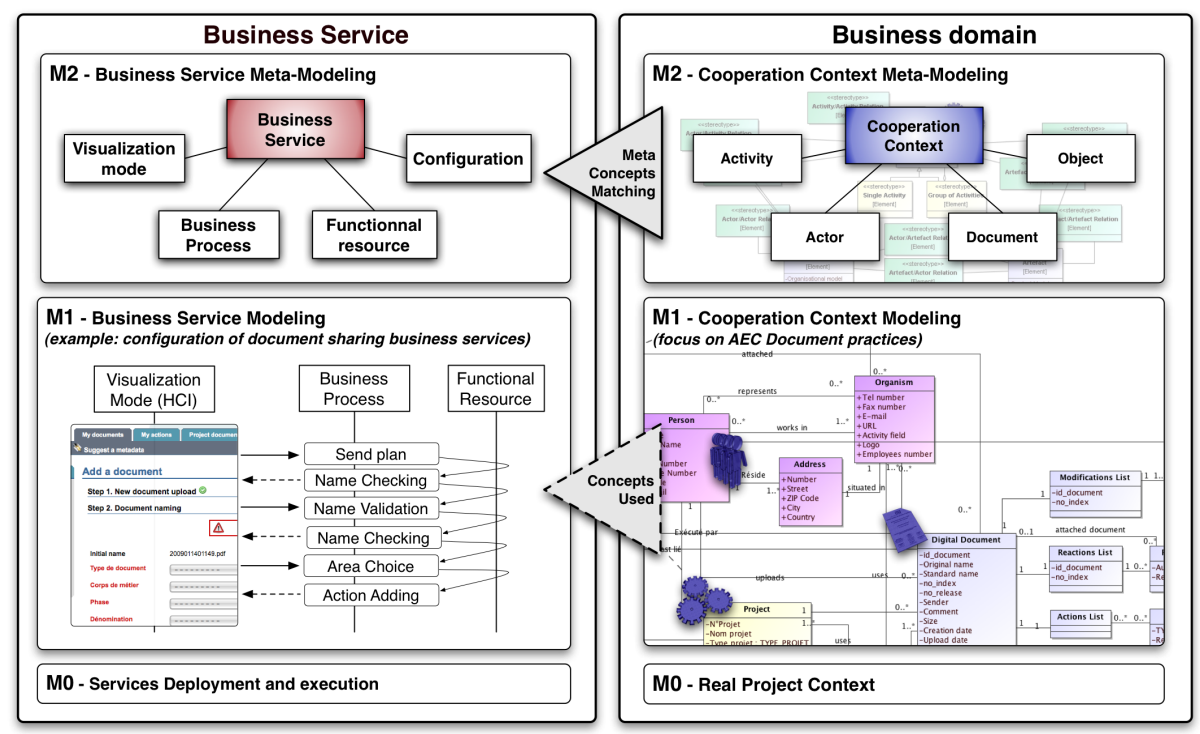

Fig. 3. A MDE approach for the design of IT services fitting a Business Domain

REST protocol [24] and are also available in SOAP. REST is a Web services technology based on the Web architecture and its basic technologies: HTTP, URI and XML. We structured these Web services using the ROA approach (Resource Oriented Architecture) [25]. It describes a set of good practices for REST Web service design and is very adapted to our Agile development process, involving business experts, technical experts and final users.

\subsection{Validation of the Demonstrator}

The prototype implementing these document management business services is under validation in two different experimental contexts. The first one consists of real projects' experiments (3 running at the time of writing this article), where earlyadopters use the tool to support the exchange of electronic documents instead of classical ones (such as fax and email). The second one is an education context (an Architecture Master curriculum [26]), where distant architecture students working on architectural design projects (4 projects performed in fall semester 2008) use the tool to share their design documentation.

The figure 4 shows the evolution of the number of e-documents shared each week via the demonstrator. It distinguishes between real construction projects and education projects.

Figure 4 shows that the usage of such an innovative tool is increasing during the duration of each experiment. This reflects the necessary appropriation time, during which users become aware of the possibilities of the tool and progressively trust it. It corresponds also to the increasing amount of documents produced and exchanged in a construction project. 


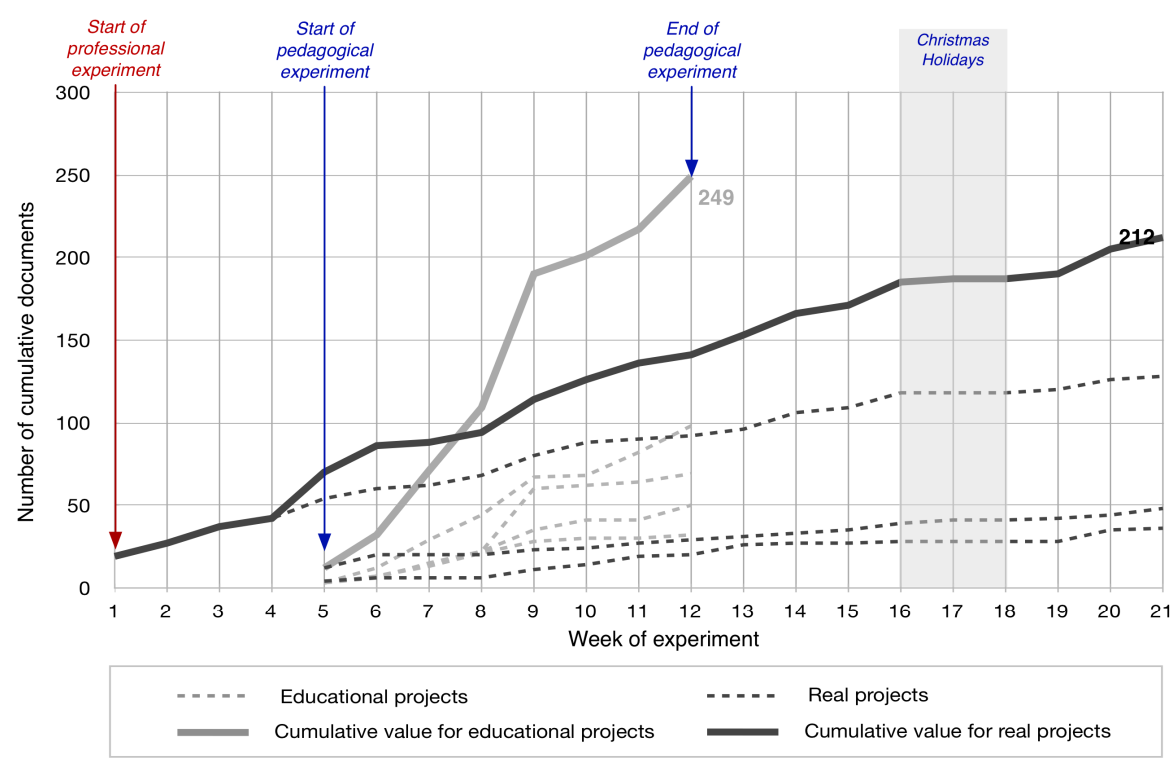

Fig. 4. Statistics of usage of the document management tool by week of experiment

Functional feedback is also targeted by the experiment stage. The cooperative practices supported by the IT services implemented seem to fit well the needs of all the practitioners of construction projects. Some particular demands came from architects and engineers (daily users of the tool), especially in order to gain time in uploading documents (addition of metadata) and to improve visualization of the documents (consultation and validation flows). Minor bugs have also been fixed.

\section{Applying a Sustainable Service Innovation in AEC}

As the result of the incremental evolutionary development and experiments of the demonstrator presented in the previous section, there has been an agreement of professional early adopters from the construction sector on the usefulness of the tool and more importantly on the added value of its offered services. Thus, the first process of the S2IP (see section 3.1) being accomplished, our role was to make sustainable this innovation by applying the next processes of the S2IP.

The challenge was thus to build a networked value constellations of actors that jointly satisfy a consumer need, where each actor contributes its own expertise and services [4]. The consumer's needs and requirements are here represented by professionals (both individuals and companies) from the AEC sector. The actors are the CRTI-B, software houses interested in selling and supporting the software services and the CRPHT. Regarding the latter, in its role of RTO, its objective is not to commercialize the developed software product derived from the demonstrator by itself but more to find partners for doing this and motivate them through the identified value proposition. 
Hereafter we describe how the networked value constellation of actors has been put in place through the realization of the remaining four processes (numbered $2-5$ in Section 3.1) of the S2IP.

2. Service design and engineering process: The first demonstrator was not robust, neither reliable enough to be transferred to a commercial software house. In our case, the benefit of the demonstrator was to help in the elicitation of the features required from the end-users and also to convince them from the usefulness of the application in support to their practices. The transfer (or selling) of a new release more stable to commercial entities is not sufficient for them. What is required is also to precisely define the set of requirements (both functional and nonfunctional) associated with the future commercial application. This precise set of requirements is required from the software house to help it in the engineering of the final product, but also from the end-users who want to check that the nice features shown through the demonstrator are also part of the final product.

3. Service promotion process: One of the mechanisms that can be used for the promotion of new services within a sector is the standardization approach. In other words, if the sector promotes an innovation as being the standard to be followed, it also strongly boosts this innovation. In our case, the CRTI-B has played this role of standardization body at national level. This was first through the endorsement of the proposed meta-data information structure for the documents. Then, from the experiments we conducted with the demonstrator, the CRTIB recognizes the importance to promote its usage in future construction projects. More importantly, the Ministry of Public Construction (one of the partners of the CRTI-B) decided to foster the use of such software services in its future public building construction projects. The CRTI-B also imposes that only a services system respecting the set of requirements formally expressed in the requirements document produced according to the process described above was eligible under its trademark "CRTI-weB".

4. Service management process: As indicated above, the role of CRPHT is not to deploy and manage the new designed services by itself. However its role is to support partners in a successful commercialization of the innovation. In our case there is today 5 consultancy software houses which are interested to develop a software system offering the services defined according to the requirements document produced by CRPHT. What they are also interested in is to demonstrate that their developed software is compliant with requirements endorsed by CRTI-B (see above). This is also what the CRTI-B expects from the proposed software. To this end it has mandated the CRPHT in its quality of neutral actor, to check for the compliance of the different proposed solutions with the requirements document. So only the companies, which will have produced a 'certified' product, will get the CRTI-B label. To do this certification approach, the CRPHT is applying a service/software procurement approach based a systematic test of both functional and non functional requirements in order to detect and track inconsistencies.

5. Service capitalization process: CRTI-B has also asked to CRPHT for a follow-up of construction projects managed with the new document management services system. To this end a working group will be set up in order to get feedbacks coming both from the professional construction actors as well as from software houses. The objective is here to enter a Plan-Do-Check-Act (PDCA) model aiming 
at improving the set of delivered services through an agreement and the publication of new releases of the requirements document.

\section{Conclusion and Future Work}

This article presents the design of IT services for the construction sector in Luxembourg. In particular, it focuses on a specific approach based on a high implication of the AEC sector professionals through the CRTI-B national standardization body. The design of an innovative document management IT services system demonstrator has been realized according to the Model-Driven Engineering, paradigm enabling the modeling of the business domain, and the rapid prototyping of the services. This development is carried out in the framework of a Sustainable Service Innovation Process (S2IP) driving the various R\&D projects of CRP Henri Tudor.

Besides a continuous improvement and formalization of the S2IP through the capitalization of other innovations performed in the context of open networks of stakeholders, more technical work is pursued in two directions.

- First, we are opening the document management services to other information systems, especially the ones used internally by some of our partners (e.g. engineering firms). The required interoperability between the global document management solution and these particular services is an essential key to guarantee a large usage of the application in Luxembourgish construction projects.

- Second, we are also addressing several research issues related to the development of these services. In particular we plan to improve the description of IT services (modeling) and of the business domain use cases (cooperation context models, M1). Our aim is to setup a repository of M1 business models, enabling the selection/discovery of IT services closely related to the specificities of these business contexts. In the construction domain it will allow us to provide IT services' offers fitting the particular context of each architectural project.

\section{Acknowledgements}

The authors would like to thank the CRTI-B network and more especially the practitioners who participated in working groups and took part in real-world experiments.

\section{References}

1. Kubicki, S., Guerriero, A., Halin, G.: Model-based eServices for supporting Cooperative Practices in AEC. In: ECPPM 2008 Conference. E-Business and e-work in Architecture, Engineering and Construction. Sophia-Antipolis, France (2008)

2. Kubicki, S., Guerriero, A., Halin, G., Hanser, D.: IT services design to support coordination practices in the Luxembourguish AEC sector. In: Luo, Y. (ed.) CDVE 2007. LNCS, vol. 4674, pp. 396-403. Springer, Heidelberg (2007) 
3. Chesbrough, H.: The era of open innovation. MIT Sloan Management Review 44(3), 35$41(2003)$

4. Tapscott, D., Ticoll, D., Lowy, A.: Digital Capital: Harnessing the Power of Business Webs. Nicholas Brealy Publishing, London (2000)

5. Kubicki, S.: Assister la coordination flexible de l'activité de construction de bâtiment. Une approche par les modèles pour la proposition d'outils de visualisation du contexte de coopération, PhD Thesis, Université Henri Poincaré, CRAI - Centre de Recherche en Architecture et Ingénierie, Nancy (2006)

6. Soley, R.: OMG: Model Driven Architecture, Object Management Group (2000)

7. Bézivin, J.: On the Unification Power of Models. Software and Systems Modelling (SoSym) 4(2), 171-188 (2005)

8. Favre, J.M.: Towards a Basic Theory to Model Driven Engineering. In: Workshop on Software Model Engineering, WISME 2004, joint event with UML2004. Lisboa, Portugal (2004)

9. Frankel, D.: Model Driven Architecture: Applying MDA to Enterprise Computing. OMG Press (2003)

10. Halin, G., Kubicki, S.: Une approche par les modèles pour le suivi de l'activité coopérative de construction d'un bâtiment. In: Augeraud, M. (ed.) Une interface multivue et des services métiers orientés gestion de chantier, in RSTI série ISI (Ingénierie des Systèmes d'Information). Modèles, formalismes et outils pour les systèmes d'information, Lavoisier, Paris (2008)

11. Kubicki, S., Bignon, J.C., Halin, G., Humbert, P.: Assistance to building construction coordination. Towards a multi-view cooperative platform. ITcon Electronic Journal of Information Technology in Construction 11, 565-586 (2006); (Special Issue Process Modelling, Process Management and Collaboration, edited by Katranuschkov, P.)

12. Hanser, D.: Proposition d'un modèle d'auto coordination en situation de conception, application au domaine du bâtiment, PhD Thesis, Institut National Polytechnique de Lorraine, CRAI - Centre de Recherche en Architecture et Ingénierie, Nancy (2003)

13. Dodgson, M., Gann, D., Salter, A.: Think, Play, Do: Technology, Innovation and Organization. University of Oxford Press, Oxford (2005)

14. Absil, F., Dubois, E., Grein, L., Michel, J.-P., Rousseau, A.: Trust in the Heart of the Open Innovation: Lessons by the Resource Centre for Information Technologies for the Building Industry. In: International Society for Professional Innovation Management (ISPIM) (2008)

15. Chesbrough, H., Spohrer, J.: A research manifesto for services science. Communications of the ACM 49(7), 35-40 (2006)

16. Caldas, C., Soibelman, L.: Automating hierarchical document classification for construction management information systems. Automation in Construction 12, 395-406 (2003)

17. Forcada, N., Casals, M., Roca, X., Gangolells, M.: Adoption of web databases for document management in SMEs of the construction sector in Spain. Automation in Construction 16, 411-424 (2007)

18. Turk, Z., Bjork, B.-C.: Document Management Systems as an Essential Step towards CIC. In: CIB-W78 Conference 1994, Helsinki, Finland (1994)

19. Nitithamyong, P., Skibniewski, M.J.: Web-based construction project management systems: how to make them successful? Automation in Construction 13, 491-506 (2004)

20. Nitithamyong, P., Skibniewski, M.J.: Key Success/Failure Factors and their Impacts on System Performance of Web-Based project Management Systems in Construction. ITcon Electronic Journal of Information Technology in Construction 12, 39-59 (2007) 
21. Björk, B.-C.: The Impact of Electronic Document Management on Construction Information Management. In: CIB-W78 Conference 2002. Aarhus School of Architecture (2002)

22. Katranuschkov, P., Scherer, R., Turk, Z.: Intelligent services and tools for concurrent engineering? An approach towards the next generation of collaboration platforms. ITcon Electronic Journal of Information Technology in Construction 6, 111-128 (2001); (Special Issue Information and Communication Technology Advances in the European Construction Industry)

23. Angulo, I., Garcia, E., Peña, N., Sanchez, V.: E-nvisioning the participation of European construction SMEs in a future e-Business scenario. In: ECPPM 2006, E-Business and ework in Architecture, Engineering and Construction, Valencia, Spain (2006)

24. Fielding, R.T.: Architectural Styles and the Design of Network-based Software Architectures, PhD Thesis, University of California, Irvine, USA (2000)

25. Richardson, L., Ruby, S.: RESTful Web Services. Web Services for the Real World. O'Reilly, Sebastopol (2007)

26. Kubicki, S., Bignon, J.C., Leclercq, P.: Cooperative Digital Studio: IT-supported Cooperation for AEC students. In: CIB-W78 2008 Improving the management of construction projects through IT adoption. Santiago de Chile, Chile (2008) 